\title{
Antimicrobial Resistance of Enterococcal Isolates from Blood and Risk Factors for Vancomycin Resistant Enterococcal Bacteremia in a Tertiary Care University Hospital from 2003 to 2007
}

\author{
Kyung Sun Park', Myeong Hee Kim², Tae Sung Park', Jin Tae Suh ${ }^{1}$, Hee Joo Lee ${ }^{1}$ \\ Department of Laboratory Medicine, ${ }^{1}$ Kyung Hee University Medical Center, ${ }^{2}$ Kyung Hee University \\ East West Neo Medical Center, Kyung Hee University College of Mediicne, Seoul, Korea
}

Background: In Korea, a sudden increase in vancomycin-resistant enterococci (VRE) infection has been noted since the late 1990 s. This study was conducted to describe the antimicrobial resistances of enterococcal blood isolates and to identify risk factors associated with VRE bacteremia in a tertiary care university hospital over a recent five-year period.

Methods: This study was conducted to analyze the antimicrobial susceptibilities of enterococcal blood isolates by year from January 2003 to December 2007. Multivariate logistic regression analysis was used to investigate factors associated with VRE bacteremia.

Results: A total of 225 enterococcal strains $(44.7 \%$ Enterococcus faecalis, 42.4\% Enterococcus facium, $5.9 \%$ Enterococcus casseliflavus, and $4.7 \%$ Enterococcus gallinarum) were detected in blood, 55 of which $(21.6 \%)$ were resistant to vancomycin. In 2004 and 2005 , the resistance rates for vancomycin and teicoplanin $(33.3 \%$ and $27.3 \%$; $34.4 \%$ and $23.0 \%$, respectively) increased. In 2003, 2006, and 2007, the resistance rates for vancomycin and teicoplanin $(8.7 \%$ and $8.7 \% ; 19.0 \%$ and $14.3 \% ; 13.5 \%$ and $11.5 \%$, respectively) decreased relative to those of the previous years. When 55 patients with VRE bacteremia were compared with 55 patients with vancomycin-susceptible enterococcal bacteremia using multivariate analysis, E. faecium bacteremia (OR 12.624, $P<0.001)$ and enterococcal bacteremia caused by species other than $E$. faecium and $E$. faecalis (OR 21.473, $P=0.011$ ) were found to be statistical risk factors. Among several infection control activities, the restricted uses of vancomycin and quinupristin-dalfopristin decreased the vancomycin resistance rate from $27.78 \%$ to $15.50 \%(P=0.0257)$. Conclusion: VRE bacteremia would be effectively controlled via infection control activities based on studies regarding risk factors associated with VRE bacteremia. (Korean J Clin Microbiol 2010;13:59-67)

Key Words: Vancomycin-resistant enterococcus (VRE), Enterococcal bacteremia, Antimicrobial resistance, Risk factors

\section{서 론}

장알균(Enterococci)은 인간과 동물에 있어 정상 장내 상재균 으로, 지난 20 여 년 동안 가장 흔한 병원 감염의 원인균 중의 하나로 여겨졌다[1]. 특히 여러 연구에서 장구균의 $\beta$-lactams 계 제제, 고농도 aminoglycoside계 제제 및 glycopeptide계 제제 등에 대한 내성률이 증가하고 있음이 밝혀졌다[2,3].

Glycopeptide계 항균제 내성인 장알균은 1988년에 처음 보고

Received 9 October, 2009, Revised 12 March, 2010

Accepted 20 April, 2010

Correspondence: Hee Joo Lee, Department of Laboratory Medicine, Kyung Hee University Medical Center, 1, Hoegi-dong, Dongdaemungu, Seoul 130-702, Korea. (Tel) 82-2-958-8672, (Fax) 82-2-9588609, (E-mail) leehejo@khmc.or.kr
[4]된 이래 전 세계적으로 꾸준히 증가하였으며, 국내에서는 1992년에 처음 vancomycin-resistant enterococcus (VRE)가 보 고[5]되었고 그 후 꾸준히 증가하여 병원 내 감염 관리의 중요 한 대상균 중의 하나가 되었다. 주요 병원에서 vancomycin 내 성의 주요 균주인 Enterococcus faecium 의 약 $20 \%$ 가 vancomycin에 내성을 보이고 있다[6].

$\mathrm{VRE}$ 에 의한 감염은 포도알균이나 사슬알균과 같은 다른 그 람양성알균에 vancomycin 내성이 전이될 수 있으며 VRE 균혈 증의 경우 약 $30 \sim 80 \%$ 정도의 높은 사망률이 보고되고 있어 임상적으로 중요한 의미를 갖는다[7-11]. 현재 VRE에 의한 감 염에 대해 quinupristin-dalfopristin, linezolid, daptomycin, tigecycline 등의 항균제가 치료제로 제시되고 있으나 그 중 일부만 이 국내 사용이 가능하고 국내의 보험인정기준상 균혈증 이외 
의 감염증에 적극적으로 사용하고 있지는 못한 실정이다.

본 연구에서는 한 대학 병원의 최근 5 년간 혈액배양에서 분 리된 vancomycin 내성 장알균의 검출률 및 내성률의 변화 추이 를 알아보고, VRE 균혈증 환자와 vancomycin susceptible enterococcus (VSE) 균혈증 환자를 비교하여 VRE 균혈증 감염의 위험 요소 및 병원 역학적 원인을 알아보고자 하였다.

\section{대상 및 방법}

\section{1. 대상 균주 및 항균제 감수성 검사}

2003년 1월부터 2007년 12월까지 혈액에서 장알균이 분리된 환자를 대상으로 하였으며 중복으로 분리된 경우는 한 개로 간 주하였다. 균종 동정과 항균제 감수성 검사는 Microscan (Dade Behring, West Sacramento, CA, USA)과 Vitek GPI card (Gram-Positive Identification: bioMérieux, Inc., Hazelwood, $\mathrm{MO}, \mathrm{USA}$ ), 전통적인 생화학 방법 및 Clinical and Laboratory Standards Institute (CLSI)에 따른 디스크 확산법[12]을 이용하 였다.

\section{VRE 균혈증과 VSE 균혈증의 임상적 특성 비교 및 병원 역 학적 특징}

$\mathrm{VRE}$ 균혈증 환자와 VSE 균혈증 환자를 비교하여 VRE 균 혈증 감염의 위험 요소를 알아보기 위해 환자의 의무기록을 후 향적으로 조사하였다. VRE 환자군의 대조군인 VSE 환자군은 $\mathrm{VRE}$ 환자군과 유의한 차이를 보이지 않는 성별 $(P=0.8487$, chi-square test)과 나이 $(P=0.7014$, t-test $)$ 로 구성되었으며 무작 위로 선별되었다. 또한 VSE 균혈증 환자와 VRE 균혈증 환자 간에는 임상적 특성에 따라 VSE 균혈증과 VRE 균혈증의 감수 성에 차이가 있을 것이라는 가정 하에 환자들의 혈액 검사 수 치를 비교하였다. 이러한 통계학적 분석에는 SPSS statistical package version 12.0 (SPSS Inc., Chicago, IL, USA)을 이용하 였다. 단변량 분석에서 빈도수에 대한 검정은 chi-square 분석 과 Fisher's exact 분석을 이용하였으며 연속변수에 대한 검정
은 독립표본 $\mathrm{t}$ 검정을 실시하였다. 그리고 단변량 분석에서 $P$ $<0.1$ 의 결과를 가진 모든 변수를 도입하여 입력(enter)의 방법 으로 다변량 로지스틱 회귀 분석을 실시하여 $P<0.05$ 인 경우를 통계적으로 유의한 차이가 있다고 판단하였다. 또한 연구 기간 중 본 대학 병원의 특정 감염관리 정책 및 병원 환경의 변화에 따른 항균제 내성률 변화를 조사하였다. 2005년 10월부터 vancomycin과 quinupristin-dalfopristin의 항균제 사용을 제한하였 고 2006년 11월 중환자실에서의 Acinetobacter baumannii 집단 발생(outbreak)으로 인해 중환자실에서의 보호장비 착용, 손씻 기 및 장갑 착용 등에 대한 교육 및 정책을 강화하였으며 연구 가 진행된 기간 중 4개의 병동에서는 리모델링(remodeling)이 진행되었다. 이러한 정책으로 인한 vancomycin 내성률의 전후 차이는 chi-square 분석과 Fisher's exact 분석을 이용하였으며 $P<0.05$ 인 경우 통계적으로 유의한 차이가 있다고 판단하였다.

\section{결 과}

\section{1. 혈액 배양에서 장구균의 분포 및 항균제 감수성 검사}

2003년부터 2007년까지 최근 5년간 혈액에서 255균주의 장 알균이 분리되었으며, E. faecalis $44.7 \%$, E. faecium $42.4 \%$, E. casseliflavus $5.9 \%$ 및 E. gallinarum $4.7 \%$ 가 분리되었다. 연도 별로 볼 때 2003년, 2006년 및 2007년에는 E. faecalis가 각각 $54.3 \%, 42.9 \%$ 및 $55.8 \%$ 로 가장 많은 수를 차지하였으며 $E$. faecium 이 각각 $41.3 \%, 38.1 \%$ 및 $25.5 \%$ 로 두 번째로 분리되었 다. 이에 비해 2004년과 2005년에는 E. faecium이 각각 54.5\%, $55.7 \%$ 로 분리되었으며, E. faecalis가 각각 $39.4 \%, 32.8 \%$ 를 차 지하였다(Table 1). Tetracycline을 제외한 ampicillin, penicillin $\mathrm{G}$, vancomycin, teicoplanin, erythromycin, ciprofloxacin에서 $E$. faecium의 항균제 내성률이 E. faecalis보다 더 높았으며, 1균주 의 E. casseliflavus를 제외하고는 linezolid에 내성을 보이는 장 알균은 없었다(Table 2). 혈액에서 분리된 255균주의 장알균 중 VRE는 모두 55균주(21.6\%)로 연도별로 볼 때, 2004년과 2005 년에는 vancomycin과 teicoplanin의 내성률이 각각 $33.3 \%$ 와

Table 1. Distribution of enterococcal species in blood culture according to years

\begin{tabular}{lccccc}
\hline & \multicolumn{6}{c}{ No. (\%) of Enterococcus species recovered } \\
\cline { 2 - 6 } Year & E. faecalis & E. faecium & E. casseliflavus & E. gallinarum & Other species* \\
\hline $2003(\mathrm{~N}=46)$ & $25(54.3)$ & $19(41.3)$ & $0(0.0)$ & $2(4.3)$ & $0(0.0)$ \\
$2004(\mathrm{~N}=33)$ & $13(39.4)$ & $18(54.5)$ & $0(0.0)$ & $0(0.0)$ & $2(6.1)$ \\
$2005(\mathrm{~N}=61)$ & $20(32.8)$ & $34(55.7)$ & $3(4.9)$ & $4(6.6)$ & $0(0.0)$ \\
$2006(\mathrm{~N}=63)$ & $27(42.9)$ & $24(38.1)$ & $7(13)$ & $6(9.5)$ & $1(1.6)$ \\
$2007(\mathrm{~N}=52)$ & $29(55.8)$ & $108(42.4)$ & $15(5.9)$ & $0(0.0)$ & $3(5.8)$ \\
Total $(\mathrm{N}=255)$ & $114(44.7)$ & $12(4.7)$ & $6(2.4)$ \\
\hline
\end{tabular}

*Other species included Enterococcus avium, Enterococcus hirae, and Enterococcus raffinosus.

Abbreviations: E. faecium, Enterococcus faecium; E. faecalis, Enterococcus faecalis; E. casseliflavus, Enterococcus casseliflavus; E. gallinarum, Enterococcus gallinarum. 
Table 2. Antimicrobial resistance rates of enterococcal isolates

\begin{tabular}{|c|c|c|c|c|c|c|}
\hline $\begin{array}{l}\text { Antimicrobial } \\
\text { agent }\end{array}$ & $\begin{array}{c}\text { E. faecalis } \\
(\mathrm{N}=114) \\
\%(\mathrm{~N})\end{array}$ & $\begin{array}{c}\text { E. faecium } \\
(\mathrm{N}=108) \\
\%(\mathrm{~N})\end{array}$ & $\begin{array}{c}\text { E. casseliflavus } \\
(\mathrm{N}=15) \\
\%(\mathrm{~N})\end{array}$ & $\begin{array}{l}\text { E. gallinarum } \\
(\mathrm{N}=12) \\
\%(\mathrm{~N})\end{array}$ & $\begin{array}{l}\text { Other species* } \\
\qquad \begin{array}{c}(\mathrm{N}=6) \\
\%(\mathrm{~N})\end{array}\end{array}$ & $\begin{array}{c}\text { Total } \\
(\mathrm{N}=255) \\
\%(\mathrm{~N})\end{array}$ \\
\hline Ampicillin & $3.5(4 / 114)$ & $79.6(86 / 108)$ & $80.0(12 / 15)$ & $100.0(12 / 12)$ & $33.3(2 / 6)$ & $45.5(116 / 255)$ \\
\hline Penicillin $\mathrm{G}$ & $23.1(15 / 65)$ & $86.2(50 / 58)$ & $86.7(13 / 15)$ & $100.0(10 / 10)$ & $50.0(2 / 4)$ & $59.2(90 / 152)$ \\
\hline Vancomycin & $7.9(9 / 114)$ & $37.0(40 / 108)$ & $13.3(2 / 15)$ & $33.3(4 / 12)$ & $0.0(0 / 6)$ & $21.6(55 / 255)$ \\
\hline Teicoplanin & $7.9(9 / 114)$ & $26.9(29 / 108)$ & $13.3(2 / 15)$ & $16.7(2 / 12)$ & $0.0(0 / 6)$ & $16.5(42 / 255)$ \\
\hline Erythromycin & $77.9(74 / 95)$ & $94.7(72 / 76)$ & $85.7(12 / 14)$ & $100.0(5 / 5)$ & $50.0(1 / 6)$ & $83.7(164 / 196)$ \\
\hline Ciprofloxacin & $53.5(61 / 114)$ & $90.7(98 / 108)$ & $80.0(12 / 15)$ & $100.0(12 / 12)$ & $16.7(0 / 6)$ & $71.8(783 / 255)$ \\
\hline Quinupristin-dalfopristin & NT & $8.6(5 / 58)$ & $20.0(3 / 15)$ & $0.0(0 / 10)$ & $50.0(2 / 4)$ & $11.5(10 / 87)$ \\
\hline Linezolid & $0.0(0 / 21)$ & $0.0(0 / 32)$ & $33.3(1 / 3)$ & $0.0(0 / 8)$ & NT & $1.6(1 / 64)$ \\
\hline Tetracycline & $76.6(59 / 77)$ & $23.0(17 / 74)$ & $6.7(1 / 15)$ & $30.0(3 / 10)$ & $33.3(2 / 6)$ & $45.1(82 / 182)$ \\
\hline
\end{tabular}

*Other species included Enterococcus avium, Enterococcus hirae, and Enterococcus raffinosus.

Abbreviations: NT, not tested; See Table 1.

Table 3. Glycopeptides, quinupristin-dalfopristin, and linezolid resistance of enterococcal isolates according to years

\begin{tabular}{|c|c|c|c|c|c|c|c|}
\hline \multirow{2}{*}{$\begin{array}{l}\text { Antimicrobial } \\
\text { agents }\end{array}$} & \multirow{2}{*}{$\begin{array}{c}\text { Enterococci } \\
\text { species }\end{array}$} & \multicolumn{6}{|c|}{ Resistance rates according to year, \% (N) } \\
\hline & & $2003(\mathrm{~N}=46)$ & $2004(\mathrm{~N}=33)$ & $2005(\mathrm{~N}=61)$ & $2006(\mathrm{~N}=63)$ & $2007(\mathrm{~N}=52)$ & Total $(\mathrm{N}=255)$ \\
\hline \multirow[t]{6}{*}{ Vancomycin } & E. faecalis & $4.0(1 / 25)$ & $15.4(2 / 13)$ & $15.0(3 / 20)$ & $3.7(1 / 27)$ & $6.9(2 / 29)$ & $7.9(9 / 114)$ \\
\hline & E. faecium & $15.8(3 / 19)$ & $50.0(9 / 18)$ & $44.1(15 / 34)$ & $33.3(8 / 24)$ & $38.5(5 / 13)$ & $37.0(40 / 108)$ \\
\hline & E. casseliflavus & - & - & $33.3(1 / 3)$ & $20.0(1 / 5)$ & $0.0(0 / 7)$ & $13.3(2 / 15)$ \\
\hline & E. gallinarum & $0.0(0 / 2)$ & - & $50.0(2 / 4)$ & $33.3(2 / 6)$ & - & $33.3(4 / 12)$ \\
\hline & Other species* & - & $0.0(0 / 2)$ & - & $0.0(0 / 1)$ & $0.0(0 / 3)$ & $0.0(0 / 6)$ \\
\hline & Total & $8.7(4 / 46)$ & $33.3(11 / 33)$ & $34.4(21 / 61)$ & $19.0(12 / 63)$ & $13.5(7 / 52)$ & $21.6(55 / 255)$ \\
\hline \multirow[t]{6}{*}{ Teicoplanin } & E. faecalis & $4.0(1 / 25)$ & $15.4(2 / 13)$ & $15.0(3 / 20)$ & $3.7(1 / 27)$ & $6.9(2 / 29)$ & $7.9(9 / 114)$ \\
\hline & E. faecium & $15.8(3 / 19)$ & $38.9(7 / 18)$ & $29.4(10 / 34)$ & $20.8(5 / 24)$ & $30.7(4 / 13)$ & $26.9(29 / 108)$ \\
\hline & E. casseliflavus & - & - & $33.3(1 / 3)$ & $20.0(1 / 5)$ & $0.0(0 / 7)$ & $13.3(2 / 15)$ \\
\hline & E. gallinarum & $0.0(0 / 2)$ & - & $0.0(0 / 4)$ & $33.3(2 / 6)$ & - & $16.7(2 / 12)$ \\
\hline & Other species* & - & $0.0(0 / 2)$ & - & $0.0(0 / 1)$ & $0.0(0 / 3)$ & $0.0(0 / 6)$ \\
\hline & Total & $8.7(4 / 46)$ & $27.3(9 / 33)$ & $23.0(14 / 61)$ & $14.3(9 / 63)$ & $11.5(6 / 52)$ & $16.5(42 / 255)$ \\
\hline \multirow{6}{*}{$\begin{array}{l}\text { Quinupristin- } \\
\text { dalfopristin }\end{array}$} & E. faecalis & NT & NT & NT & NT & NT & NT \\
\hline & E. faecium & NT & NT & $4.2(1 / 24)$ & $8.7(2 / 23)$ & $18.2(2 / 11)$ & $8.6(5 / 58)$ \\
\hline & E. casseliflavus & NT & NT & $33.3(1 / 3)$ & $20.0(1 / 5)$ & $14.3(1 / 7)$ & $20.0(3 / 15)$ \\
\hline & E. gallinarum & NT & NT & $0.0(0 / 4)$ & $0.0(0 / 6)$ & - & $0.0(0 / 10)$ \\
\hline & Other species* & NT & NT & - & $100.0(1 / 1)$ & $33.3(1 / 3)$ & $50.0(2 / 4)$ \\
\hline & Total & NT & NT & $6.5(2 / 31)$ & $11.4(4 / 35)$ & $19.0(4 / 21)$ & $11.5(10 / 87)$ \\
\hline \multirow[t]{6}{*}{ Linezolid } & E. faecalis & NT & NT & $0.0(0 / 13)$ & $0.0(0 / 6)$ & $0.0(0 / 2)$ & $0.0(0 / 21)$ \\
\hline & E. faecium & NT & NT & $0.0(0 / 24)$ & $0.0(0 / 7)$ & $0.0(0 / 1)$ & $0.0(0 / 32)$ \\
\hline & E. casseliflavus & NT & NT & $33.3(1 / 3)$ & NT & NT & $33.3(1 / 3)$ \\
\hline & E. gallinarum & NT & NT & $0.0(0 / 4)$ & $0.0(0 / 4)$ & - & $0.0(0 / 8)$ \\
\hline & Other species* & NT & NT & - & NT & NT & NT \\
\hline & Total & NT & NT & $2.3(1 / 44)$ & $0.0(0 / 17)$ & $0.0(0 / 3)$ & $1.6(1 / 64)$ \\
\hline
\end{tabular}

*Other species included Enterococcus avium, Enterococcus hirae, and Enterococcus raffinosus.

Abbreviations: NT, not tested; See Table 1.

$27.3 \%$ 및 34.4\%와 23.0\%로 높았으며 2003년, 2006년 및 2007 년에는 vancomycin과 teicoplanin의 내성률이 각각 $8.7 \%$ 와 $8.7 \%, 19.0 \%$ 와 $14.3 \%$ 및 $13.5 \%$ 와 $11.5 \%$ 로 2004년부터 2005년 에는 높은 비율을 보이다가 2006년부터 감소되는 양상을 보였 다(Table 3).

\section{VRE 균혈증과 VSE 균혈증의 임상적 특성 비교 및 병원 역 학적 특징}

VSE 균혈증 환자군과 VRE 균혈증 환자군에서 질병의 중등 도를 평가하기 위해 Charlson comorbidity index (CCI)를 사용 하여 비교한 결과 두 군과의 차이(weighted index comorbidity: $P=0.7418$, t-test; combined condition and age related score: 
Table 4. Univariate analysis of demographic and clinical data between patients with vancomycin-resistant enterococcal (VRE) bacteremia and those with vancomycin susceptible enterococcal (VSE) bacteremia

\begin{tabular}{|c|c|c|c|}
\hline Variables & $\begin{array}{c}\mathrm{VRE} \\
(\mathrm{N}=55)^{*}\end{array}$ & $\begin{array}{c}\mathrm{VSE} \\
(\mathrm{N}=55)^{*}\end{array}$ & $P^{\dagger}$ \\
\hline Gender, $\mathrm{M}: \mathrm{F}$ & $27: 28$ & $29: 26$ & 0.849 \\
\hline $\begin{array}{l}\text { Age in years, } \\
\text { mean } \pm \mathrm{SD}\end{array}$ & $59.69 \pm 19.31$ & $61.07 \pm 18.38$ & 0.701 \\
\hline \multicolumn{4}{|l|}{ Ward } \\
\hline ICU & 28 & 32 & 0.792 \\
\hline MICU & 10 & 12 & \\
\hline SICU & 6 & 5 & \\
\hline NICU & 12 & 15 & \\
\hline Non-ICU & 27 & 23 & \\
\hline Hemato-onco ward & 3 & 1 & \\
\hline General ward & 24 & 22 & \\
\hline $\begin{array}{l}\text { Hospital stay (day), } \\
\text { mean } \pm \text { SD }\end{array}$ & $64.45 \pm 66.38$ & $63.05 \pm 49.93$ & 0.889 \\
\hline \multicolumn{4}{|l|}{ Invasive procedure } \\
\hline Urinary catheter & 44 & 49 & 0.291 \\
\hline Central line & 34 & 34 & 1.000 \\
\hline Ventilator & 33 & 21 & $0.035^{\ddagger}$ \\
\hline L-tube & 36 & 38 & 0.839 \\
\hline Surgery & 25 & 26 & 1.000 \\
\hline \multicolumn{4}{|l|}{ Underlying disease } \\
\hline Diabetes mellitus & 12 & 19 & 0.203 \\
\hline Hypertension & 17 & 22 & 0.426 \\
\hline Tuberculosis & 3 & 1 & 0.618 \\
\hline Cancer & 6 & 5 & 1.000 \\
\hline Renal insufficiency & 9 & 8 & 1.000 \\
\hline Polymicrobial infection & 50 & 42 & 0.069 \\
\hline Polymicrobial bacteremia & 6 & 5 & 1.000 \\
\hline \multicolumn{4}{|l|}{ Causative organism } \\
\hline E. faecium & 43 & 23 & $<0.001^{\ddagger}$ \\
\hline E. faecalis & 6 & 30 & \\
\hline Other species & 6 & 2 & \\
\hline $\begin{array}{l}\text { Known source of } \\
\text { bacteremia }\end{array}$ & 12 & 4 & 0.056 \\
\hline Urinary tract & 4 & 4 & \\
\hline Gastointesital tract & 5 & 0 & \\
\hline Others & 3 & 0 & \\
\hline MRSA co-infection & 14 & 10 & 0.489 \\
\hline \multicolumn{4}{|l|}{$\begin{array}{l}\text { Prior exposure with } \\
\text { antibiotics }\end{array}$} \\
\hline Vancomycin & 31 & 12 & $<0.001^{\ddagger}$ \\
\hline Quinolone & 20 & 21 & 1.000 \\
\hline Imipenem & 9 & 1 & $0.016^{\ddagger}$ \\
\hline Penicillin & 28 & 15 & $0.019^{\ddagger}$ \\
\hline Cephalosporin & 42 & 36 & 0.294 \\
\hline Aminoglycoside & 30 & 26 & 0.567 \\
\hline Clindamycin & 12 & 12 & 1.000 \\
\hline
\end{tabular}

*We used the Charlson comorbidity index to evaluate the disease severity and comorbidity in VRE group and VSE group. There were not statistically different in disease severity and comorbidity between VRE group and VSE group (Weighted index comorbidity: $P=0.7418$, t-test; Combined condition and age related score: $P=0.5240$, t-test); ${ }^{\dagger}$ A univariate analysis was carried out by the chi-square test or Fisher's exact test depending on the sample size for qualitative variables. Continuous variables were analyzed with t-test; ${ }^{f}$ Statistical significance.

Abbreviations: SD, standard deviation; ICU, intensive care unit; MICU, medical intensive care unit; SICU, surgical intensive care unit; NICU, neurosurgical intensive care unit.
$P=0.5240$, t-test)는 발견되지 않았다. VSE 균혈증 환자와 비교 하여 VRE 균혈증 환자에서의 위험요소 및 임상적 특성을 살펴 볼 때, 인공 호흡기 사용시 $(P=0.035)$, 균혈증의 원인균 차이 $(P$ $<0.001)$, 이전에 vancomycin $(P<0.001)$, imipenem $(P=0.016)$ 및 penicillin $(P=0.019)$ 의 항균제로 치료하였던 경우가 단변량 분석에서 통계적으로 유의한 위험 요인으로 분석되었다(Table 4). 또한 VSE 균혈증 환자와 VRE 균혈증 환자간에 혈액 검사 수치를 비교 시, sodium 수치의 차이 $(P=0.047)$ 와 혈소판 수치 의 차이 $(P=0.027)$ 가 단변량 분석에서 $\mathrm{VRE}$ 균혈증의 유의한 위 험요인으로 분석되었다(Table 5). 단변량 분석에서 $P<0.1$ 인 변 수들을 모두 도입하여 다변량 로지스틱 회귀분석을 실시한 결 과 E. faecium 균혈증인 경우(odds ratio $12.624,95 \%$ confident interval 3.398 46.895, $P<0.001)$ 와 E. faecium와 E. faecalis를 제외한 다른 장알균에 의한 균혈증인 경우(OR $21.473,95 \%$ CI $2.038 \sim 226.275, P=0.011)$ 만이 유의한 위험 요인으로 분석되었 다(Table 6).

또한 본 병원의 특정 감염관리 정책 및 병원 환경의 변화에 따른 vancomycin 내성률 변화를 볼 때, vancomycin과 quinupristin-dalfopristin의 항균제 사용을 제한하는 정책을 시행한 이 후 VRE 내성률이 유의한 차이 $(P=0.0257)$ 를 보이며 감소되는 양상을 보였다(Table 7). 그러나 이러한 정책에 의한 vancomycin 내성률 변화를 장알균의 주요 균종인 E. faecalis와 E. faecium 으로 나누어 확인했을 때, 유의한 차이 $(P=0.3733, P=$ 0.8459 , 각각)를 보이지 않았다.

\section{고 찰}

최근 국내의 몇몇 대학병원에서 몇 년 동안의 혈액배양에서 분리된 미생물의 분포에 대한 보고가 있었다. 혈액배양에서 분 리된 장알균의 분포만을 고려해 볼 때, Koh 등[13]의 연구에서 전체 장알균 중 E. faecalis가 $40.0 \%$ (808균주 중 323균주), E. faecium이 $52.2 \%$ (808균주 중 422균주)이었고, Kang과 $\operatorname{Kim}[14]$ 의 연구에서는 E. faecalis 가 $30.6 \%$ (111균주 중 34균 주), E. faecium이 25.2\% (111균주 중 28균주)이었으며, Ahn 등 [15]의 연구에서는 E. faecalis가 44\% (50균주 중 22균주), $E$. faecium이 $38 \%$ (50균주 중 19균주)가 검출되었다. 미국의 Surveillance Network (TSN) Database[16]는 혈액배양에서 $E$. faecalis : E. faecium이 $2.5: 1.0$ 으로 분리되었다고 보고한 바 있는데, 국내에서 발표된 연구들을 미루어볼 때 E. faecium이 국외보다 국내에서 더 많은 비율로 분리되는 것을 확인할 수 있었다. 또한 본 연구에서도 2003년부터 2007년까지 혈액배양 에서 E. faecalis가 $44.7 \%$ (255균주 중 114균주), E. faecium이 $42.4 \%$ (255균주 중 108균주)가 분리되어 이러한 사실을 확인 할 수 있었다.

본 연구에서 혈액배양에서 분리된 장알균의 ampicillin의 내 
Table 5. Univariate analysis of laboratory data between patients with vancomycin-resistant enterococcal (VRE) bacteremia and those with vancomycin susceptible enterococcal (VSE) bacteremia

\begin{tabular}{|c|c|c|c|}
\hline Variables & $\begin{array}{c}\mathrm{VRE}(\mathrm{N}=55)^{*} \\
\text { mean } \pm \mathrm{SD} \text { (range) }\end{array}$ & $\begin{array}{c}\mathrm{VSE}(\mathrm{N}=55)^{*} \\
\text { mean } \pm \mathrm{SD} \text { (range) }\end{array}$ & $P^{\dagger}$ \\
\hline ALP (IU/L) & $108.96 \pm 80.5(31.0 \sim 387.0)$ & $118.80 \pm 124.81 \quad(23.0 \sim 607.0)$ & 0.650 \\
\hline Total protein $(\mathrm{g} / \mathrm{dL})$ & $5.60 \pm 0.85(3.9 \sim 7.6)$ & $5.56 \pm 0.95(3.9 \sim 7.8)$ & 0.830 \\
\hline Albumin (g/dL) & $2.69 \pm 0.56(1.6 \sim 4.0)$ & $2.64 \pm 0.56(1.8 \sim 3.9)$ & 0.696 \\
\hline AST (IU/L) & $61.15 \pm 66.18(10.0 \sim 342.0)$ & $44.20 \pm 27.44(14.0 \sim 116.0)$ & 0.116 \\
\hline ALT (IU/L) & $44.27 \pm 53.91(3.0 \sim 370.0)$ & $37.82 \pm 43.92(4.0 \sim 292.0)$ & 0.527 \\
\hline BUN (mg/dL) & $29.38 \pm 27.32(4.0 \sim 153.0)$ & $37.18 \pm 37.13(1.0 \sim 156.0)$ & 0.212 \\
\hline Creatinine $(\mathrm{mg} / \mathrm{dL})$ & $1.09 \pm 0.86(0.2 \sim 5.0)$ & $1.59 \pm 1.82(0.3 \sim 10.1)$ & 0.071 \\
\hline Sodium $(\mathrm{mmol} / \mathrm{L})$ & $135.15 \pm 5.77(123.0 \sim 149.0)$ & $137.45 \pm 6.25(120.0 \sim 152.0)$ & $0.047^{\ddagger}$ \\
\hline Potassium (mmol/L) & $3.87 \pm 0.68(2.5 \sim 5.4)$ & $3.79 \pm 0.79(1.9 \sim 6.3)$ & 0.562 \\
\hline Chloride $(\mathrm{mmol} / \mathrm{L})$ & $102.11 \pm 6.00(90.0 \sim 118.0)$ & $103.82 \pm 6.91(91.0 \sim 105.0)$ & 0.169 \\
\hline Glucose (mg/dL) & $160.14 \pm 88.40(49.0 \sim 545.0)$ & $178.44 \pm 104.22(70.0 \sim 710.0)$ & 0.368 \\
\hline WBC (count/ $\mu \mathrm{L})$ & $11,606 \pm 11,605(180.0 \sim 30,840.0)$ & $12,632 \pm 8,985(300 \sim 43,200.0)$ & 0.482 \\
\hline Hemoglobin $(\mathrm{g} / \mathrm{dL})$ & $10.13 \pm 2.14(6.1 \sim 19.3)$ & $10.45 \pm 2.12(6.5 \sim 16.6)$ & 0.433 \\
\hline Platelet (count/ $\mu \mathrm{L}$ ) & $232,055 \pm 137,822(15.0 \sim 610.0)$ & $178,218 \pm 113,651 \quad(15.0 \sim 538.0)$ & $0.027^{\dagger}$ \\
\hline $\operatorname{ESR}(\mathrm{mm} / \mathrm{hr})$ & $34.37 \pm 24.02(1.0 \sim 85.0)$ & $31.77 \pm 18.84(2.0 \sim 85.0)$ & 0.630 \\
\hline
\end{tabular}

*See Table 4; ${ }^{\dagger}$ Continuous variables were analyzed with t-test; ${ }^{\dagger}$ Statistical significance.

Abbreviations: ALP, alkaline phosphatase; AST, aspartate aminotransferase; ALT, alanine aminotransferase; BUN, blood urea nitrogen; WBC, white blood cell; ESR, erythrocyte sedimentation rate.

Table 6. Multivariate logistic regression analysis of risk factors for acquiring bacteremia caused by vancomycin-resistant enterococci (VRE)

\begin{tabular}{|c|c|c|c|c|c|c|c|c|}
\hline \multirow{2}{*}{ Variables* } & \multirow{2}{*}{$\mathrm{B}$} & \multirow{2}{*}{ S.E. } & \multirow{2}{*}{ Wald } & \multirow{2}{*}{ DOF } & \multirow{2}{*}{$P$} & \multirow{2}{*}{$\operatorname{Exp}(B)$} & \multicolumn{2}{|c|}{$95 \%$ confident interval } \\
\hline & & & & & & & Lower & Upper \\
\hline Ventilatior & 0.832 & 0.585 & 2.024 & 1 & 0.155 & 2.298 & 0.730 & 7.235 \\
\hline Polymicrobial infection & 0.623 & 0.751 & 0.690 & 1 & 0.406 & 1.865 & 0.428 & 8.123 \\
\hline \multicolumn{9}{|l|}{ Causative organism } \\
\hline E. faecalis & & & 15.226 & 2 & 0.000 & & & \\
\hline E. faecium & 2.536 & 0.670 & 14.341 & 1 & $<0.001_{ \pm}^{\ddagger}$ & 12.624 & 3.398 & 46.895 \\
\hline Other species & 3.067 & 1.202 & 6.515 & 1 & $0.011^{\ddagger}$ & 21.473 & 2.038 & 226.275 \\
\hline Known source of bacteremia & 1.266 & 1.008 & 1.576 & 1 & 0.209 & 3.547 & 0.491 & 25.600 \\
\hline Previous vancomycin therapy & 1.042 & 0.621 & 2.817 & 1 & 0.093 & 2.836 & 0.840 & 9.579 \\
\hline Previous imipenem therapy & 1.074 & 1.214 & 0.783 & 1 & 0.376 & 2.927 & 0.271 & 31.590 \\
\hline Previous penicillin therapy & 0.885 & 0.579 & 2.336 & 1 & 0.126 & 2.424 & 0.779 & 7.545 \\
\hline \multicolumn{9}{|l|}{ Creatinine $(\mathrm{mg} / \mathrm{dL})$} \\
\hline $0.6 \sim 1.2$ & & & 1.845 & 2 & 0.398 & & & \\
\hline$<0.6$ & -1.157 & 0.857 & 1.822 & 1 & 0.177 & 0.314 & 0.059 & 1.687 \\
\hline$<1.2$ & -0.097 & 0.654 & 0.022 & 1 & 0.882 & 0.908 & 0.252 & 3.269 \\
\hline \multicolumn{9}{|l|}{ Sodium $(\mathrm{mmol} / \mathrm{L})$} \\
\hline $135 \sim 145$ & & & 2.720 & 2 & 0.257 & & & \\
\hline$<135$ & 0.368 & 0.543 & 0.460 & 1 & 0.497 & 1.445 & 0.499 & 4.190 \\
\hline$>145$ & -1.926 & 1.359 & 2.010 & 1 & 0.156 & 0.146 & 0.010 & 2.088 \\
\hline \multicolumn{9}{|l|}{ Platelet $($ count $/ \mu \mathrm{L})$} \\
\hline $150,000 \sim 350,000$ & & & 7.073 & 2 & 0.029 & & & \\
\hline$<150,000$ & 1.275 & 1.436 & 0.788 & 1 & 0.375 & 3.579 & 0.215 & 59.697 \\
\hline$>350,000$ & 2.793 & 1.452 & 3.698 & 1 & 0.054 & 16.327 & 0.948 & 281.317 \\
\hline Constant $^{\dagger^{-}}$ & -5.723 & 1.807 & 10.035 & 1 & 0.002 & 0.003 & & \\
\hline
\end{tabular}

*All variables with a $P$ value of $<0.1$ in univariate analyses were included in multivariate logistic regression analysis. Multivariate logistic regression analysis was performed by enter method; ${ }^{\dagger}$ The value of the dependent variable when the independent variables are all zero; ${ }^{\ddagger}$ Statistical significance

Abbreviations: B, estimate of regression coefficient; S.E, standard error; DOF, degree of freedom; Exp(B), exponentiated B (odds ratio).

성률은 $45.5 \%$ (255균주 중 116 균주), vancomycin의 내성률은 $21.6 \%$ (255균주 중 55균주)이었다. 균종별로는 E. faecium이 ampicillin $79.6 \%$, vancomycin $37.0 \%$ 이었고 E. faecalis는 ampi- cillin 3.5\%, vancomycin 7.9\%로 E. faecium보다 내성률이 낮았 다. 본 대학병원의 1986년부터 1996년까지 혈액배양에서 분리 된 세균과 진균의 분포 및 감수성 추이의 연구[17]에서 장알균 
Table 7. Difference of vancomycin resistance rate according to infection control activities

\begin{tabular}{|c|c|c|c|}
\hline \multirow{2}{*}{ Infection control activities } & \multicolumn{2}{|c|}{ Vancomycin resistance rate } & \multirow{2}{*}{$P^{\ddagger}$} \\
\hline & Before $\%(N)$ & After $\%(\mathrm{~N})$ & \\
\hline $\begin{array}{l}\text { Application of restricted vancomycin and quinupristin-dalfopristin } \\
\text { from October } 2005^{\dagger}\end{array}$ & $27.78(35 / 126)$ & $15.50(20 / 129)$ & $0.0257^{*}$ \\
\hline $\begin{array}{l}\text { Strengthening infection control management because of } 2006 \\
\text { A. baumannii outbreak in ICU from November }\end{array}$ & $23.96(23 / 96)$ & $19.23(5 / 26)$ & 0.8060 \\
\hline \multicolumn{4}{|l|}{ Ward remodeling } \\
\hline Ward A (from April 2006 to July 2006) & $60.0(3 / 5)$ & $0.0(0 / 6)$ & 0.06 \\
\hline Ward B (from August 2006 to November 2006) & $29.41(5 / 17)$ & $0.0(0 / 1)$ & 1.0 \\
\hline Ward C (from December 2006 to March 2007) & $25.0(3 / 12)$ & $0.0(0 / 2)$ & 1.0 \\
\hline Ward D (from October 2005 to February 2006) & $25.0(2 / 8)$ & $0.0(0 / 0)$ & NT \\
\hline
\end{tabular}

*Statistical significance; ${ }^{\dagger}$ The vancomycin-resistance rates of E. faecalis and E. faecium were $11.3 \%(6 / 53)$ and $30.8 \%(20 / 65)$ before October 2005. They were $5.0 \%(3 / 60)$ and $30.9 \%(23 / 42)$ after October 2005 . However, there were not statistically different $(E$. faecalis: $P=0.3733, E$. faecium: $P=0.8459)$. Quinupristin-dalfopristin resistance rate was 37.5\% (12/32) before October 2005 and 49.15\% (58/118) after October 2005. However, there was no significant difference $(P=0.3310)$; ${ }^{\ddagger}$ Qualitative variables were analyzed with the chi-square test or Fisher's exact test depending on the sample size.

Abbreviation: NT, not tested.

의 ampicillin 감수성률이 $73 \sim 89 \%$, vancomycin이 $60 \sim 100 \%$ 임을 고려할 때, 2003년부터 2007년까지의 장알균의 ampicillin 과 vancomycin의 내성률은 유의할 만한 증가를 보였다고 할 수 있다. 2004년도에 국내 12개 병원을 대상으로 발표된 vancomyin 내성률은 E. faecalis 1\% (0 6\%), E. faecium 20\% (8 $42 \%$ )이었고[6], 2005년도 2006년도까지의 12개 병원을 대상으 로 발표된 vancomycin 내성률은 2005년도에는 E. faecalis $2 \%$, E. faecium 29\%이고 2006년도에는 E. faecalis 1\%, E. faecium $24 \%$ 이었다[18]. 또한 2003년도 KONSAR (Korean nationwide surveillance of antimicrobial resistance) 감시에서는 E. faecalis 와 E. faecium 의 vancomycin 내성률이 각각 $0.9 \%$ 와 $20 \%$ 로 보 고되었다[19]. 따라서 최근 다수의 국내 병원에서의 vancomy$\operatorname{cin}$ 내성률과 비교해 볼 때, 본 대학병원에서의 E. faecalis와 E. faecium 의 vancomycin 내성률은 다소 높은 양상을 보이고 있음 을 확인할 수 있었다.

본 연구에서 장알균의 vancomycin과 teicoplanin의 내성률이 2004년 및 2005년에는 높은 비율을 보이다가 2006년부터 비교 적 감소되는 양상을 보였다. 이것은 2004년과 2005년에는 vancomycin 내성의 주요 균종인 E. faecium 이 E. faecalis보다 많이 검출되다가 2006년부터 E. faecalis가 E. faecium보다 많이 검출 된 것이 주된 원인이라 할 수 있깄다.

이러한 변화에 영향을 미칠 수 있는 요인으로는 환자, 병원 및 환경적 요인 등으로 나뉠 수 있는데, 그 중에서 병원 내 감 염 관리정책 및 병원 환경의 변화는 주요한 요인 중 하나라 할 수 있다. 본 연구에서는 병원 내 감염 관리정책 및 병원 환경의 변화에 따른 vancomycin 내성률 변화를 조사하였는데 2005년 10 월부터 vancomycin과 quinupristin-dalfopristin의 항균제 사용 을 제한하는 정책을 시행한 이후 유의한 차이 $(P=0.026)$ 를 보이
며 내성률이 $27.78 \%$ 에서 $15.50 \%$ 으로 감소한 것을 확인할 수 있었다. 그러나 이것을 장알균의 주요 균종인 E. faecalis와 E. faecium으로 나누어 vancomycin 내성률을 확인해 보았더니 유 의한 차이 $(P=0.3733, P=0.8459$, 각각 $)$ 를 보이지 않았다. 따라서 저자들은 본 대학병원에서의 장알균의 검출률 및 내성률의 변 화는 병원의 정책적 측면만이 관여한 것이 아니라 환자의 임상 적 특성, 항균제 사용 및 병실 내 환경적 요인 등 여러 요소들 이 함께 작용했으리라 판단되었다.

Quale 등[20]은 3세대 cephalosporin, clindamycin 및 vancomycin의 사용을 제한한 경우 VRE의 유병률이 $47 \%$ 에서 $15 \%$ 로 감소함을 보고한 바 있다. 또한 2,000병상의 한 병원에서 vancomycin 내성 E. faecium의 집단 발생이 있은 후, 3세대 cephalosporin, beta-lactamase inhibitor, 혐기균 항균제 및 glycopeptide의 사용의 제한과 직장 면봉 검체를 통한 VRE 선별 검사, 병원 내 위생 정책 등의 강화 등으로 VRE의 유행을 성공 적으로 통제한 사례도 보고되었다[21].

본 연구에서 VSE 균혈증을 가진 환자와 VRE 균혈증이 있는 환자를 비교하여 VRE 균혈증 관련 위험인자를 단변량 분석으 로 분석한 결과 인공 호흡기 사용, 균혈증의 원인균 차이, 이전 에 vancomycin, imipenem 및 penicillin의 항균제로 치료하였던 경우, 혈액 내 sodium 수치의 차이 및 혈소판 수치의 차이가 위 험 요인으로 분석되었다. 그러나 다변량 로지스틱 회귀분석에서 는 E. faecium 균혈증인 경우(OR 12.624, 95\% Cl 3.398 $46.895, P<0.001)$ 와 E. faecium과 E. faecalis를 제외한 다른 장 알균에 의한 균혈증인 경우(OR 21.473, 95\% CI 2.038 $226.275, P=0.011)$ 만이 통계적으로 유의한 위험 요인으로 분석 되었다.

여러 연구에서 VRE 균혈증의 임상적 위험인자를 분석하였 
는데, 1995년부터 1997년까지 미국의 22개 병원을 대상으로 한 National Nosocomial Resistance Surveillance Group (NNRSG) 의 연구에서 AIDS/HIV 및 마약 남용(OR 9.58), 이전의 vancomycin 정맥 치료(OR 8.37), 간이식의 과거력(OR 6.75), 인공항 문형성(OR 4.85), 혈액투석용 카테터 삽입(OR 3.48), 이전의 imipenem의 치료(OR 2.86), E. faecalis의 동정(OR 0.0464), 41 64세(OR 0.326) 및 수술력(OR 0.518)이 다변량 분석에서 통 계적으로 유의한 인자로 밝혀졌다[22]. 또한 VRE 집락화에서 $\mathrm{VRE}$ 균혈증으로 이행되는 데 관여하는 위험인자에 대한 다변 량 분석에서는 혈액 외에 다른 부위의 감염이 있을 경우(OR $3.9)$, 장기요양기관에서 병원으로 입원했던 경우(OR 12.6) 및 이전에 vancomycin으로 치료하였을 경우(OR 10.6)가 통계적으 로 유의하게 차이가 있는 것으로 나왔다[23]. 그밖에 다른 요인 으로 Acute Physiology and Chronic Health Evaluation (APACHE) II 점수가 높은 경우, 혈액종양이나 골수 이식을 받 은 경우, 이전에 면역 억제 치료를 받은 경우, 이전에 cephalosporin의 치료를 받은 경우, vancomycin 내성 E. faecium의 위 장관내 집락이 형성된 경우, metronidazole, clindamycin 및 imipenem의 혐기성 항균제로 치료한 경험이 있는 경우 등이 있다 [7,24-26].

국내 한 대학병원에서 8 년 동안 vancomycin 내성 장알균 감 염 환자를 대상으로 사망에 기여하는 위험 요인에 관한 연구를 하였는데, 신기능 저하와 중심 정맥관 삽입, 기관 절개가 유의 한 위험요인으로 분석되었고 다변량 분석에서는 신기능 저하 만이 주요한 위험요인으로 분석되었다[27]. 국내 90명의 혈액 암 환자들을 대상으로 VRE 균혈증이 사망률에 기여하는 인자 들을 분석하였더니, 다변량 분석에서 중성구 수치 회복의 지연 (OR 40.29)과 높은 $\mathrm{APACH}$ II 점수(OR 1.25)가 통계적으로 유 의하게 나왔다[28]. 그러나 혈액배양에서 vancomycin에 높은 내성률을 보이는 E. faecium이 국외보다 국내에서 높은 비율로 검출되는 데 비해, 미국의 NNRSG 같이 VRE 균혈증에 관여하 는 위험인자 및 사망률 관련 예측 인자 분석에 대한 체계적인 연구가 국내에서는 아직까지 미흡한 실정이다.

이번 연구에는 해석상 몇 가지 제한점이 있다. 첫째, 이번 연 구는 한 대학병원에서 5년간 혈액배양에서 분리된 장알균을 대 상으로 연구가 후향적으로 진행이 되었기 때문에 그 결과가 보 편성이 결여될 수도 있다. 둘째, 유전형(vanA, vanB, vanC, $v a n D, v a n E$ 및 $v a n G$ )과 제한효소 절편분석법(restriction fragment length polymorphism, FRLP), ribotyping 및 PFGE (pulsed field gel electrophoresis) 등과 같은 분자 역학조사를 시행하지 못한 점이다. 또한 E. casseliflavus와 E. gallinarum은 선천적으 로 vancomycin 내성임에도 불구하고 내성률이 $13.3 \%, 33.3 \%$ 로 나왔는데 이것은 항균제 감수성 검사에서 최소억제 농도 측정 법과 디스크확산법을 혼재하여 측정하였기 때문이라 판단하였 다. 따라서 저자들은 혈액배양에서 분리된 장알균의 항균제 내
성률이 타 병원보다 본 대학병원에서 높은 것을 고려해 볼 때, 추후에 추가 검사들이 시행되어야 할 것으로 생각되었다.

그러나 한 대학병원에서의 특정 감염관리 정책 및 병원 환경 의 변화가 VRE 균혈증 감소에 미치는 영향 및 위험인자에 대 한 분석은 앞으로의 VRE 관련 감염관리에 많은 도움이 될 수 있으리라고 생각되었다. 또한 저자들은 체계적인 계획을 세운 선후향적 코호트 연구와 국내의 여러 병원들의 자료를 수집한 광범위한 연구를 바탕으로 VRE 관련 감염관리 정책이 수립된 다면 보다 성공적인 효과를 거둘 수 있으리라고 사료되었다.

\section{참 고 문 헌}

1. Kühn I, Iversen A, Finn M, Greko C, Burman LG, Blanch AR, et al. Occurrence and relatedness of vancomycin-resistant enterococci in animals, humans, and the environment in different European regions. Appl Environ Microbiol 2005;71:5383-90.

2. Grayson ML, Eliopoulos GM, Wennersten CB, Ruoff KL, De Girolami PC, Ferraro MJ, et al. Increasing resistance to beta-lactam antibiotics among clinical isolates of Enterococcus faecium: a 22-year review at one institution. Antimicrob Agents Chemother 1991;35:2180-4.

3. Oster SE, Chirurgi VA, Goldberg AA, Aiken S, McCabe RE. Ampicillin-resistant enterococcal species in an acute-care hospital. Antimicrob Agents Chemother 1990;34:1821-3.

4. Leclercq R, Derlot E, Duval J, Courvalin P. Plasmid-mediated resistance to vancomycin and teicoplanin in Enterococcus faecium. N Engl J Med 1988;319:157-61.

5. Park JW, Kim YR, Shin WS, Kang MW, Han KJ, Shim SI. Susceptibility tests of vancomycin-resistant enterococci. Korean J Infect Dis 1992;24:133-7.

6. Lee H, Yong D, Lee K, Hong SG, Kim EC, Jeong SH, et al. Antimicrobial resistance of clinically important bacteria isolated from 12 hospitals in Korea in 2004. Korean J Clin Microbiol 2005;8:66-73.

7. Shay DK, Maloney SA, Montecalvo M, Banerjee S, Wormser GP, Arduino MJ, et al. Epidemiology and mortality risk of vancomycin-resistant enterococcal bloodstream infections. J Infect Dis 1995;172:993-1000.

8. Edmond MB, Ober JF, Weinbaum DL, Pfaller MA, Hwang T, Sanford MD, et al. Vancomycin-resistant Enterococcus faecium bacteremia: risk factors for infection. Clin Infect Dis 1995;20: 1126-33.

9. Lucas GM, Lechtzin N, Puryear DW, Yau LL, Flexner CW, Moore RD. Vancomycin-resistant and vancomycin-susceptible enterococcal bacteremia: comparison of clinical features and outcomes. Clin Infect Dis 1998;26:1127-33.

10. Garbutt JM, Ventrapragada M, Littenberg B, Mundy LM. Association between resistance to vancomycin and death in cases of Enterococcus faecium bacteremia. Clin Infect Dis 2000;30:466-72.

11. Erlandson KM, Sun J, Iwen PC, Rupp ME. Impact of the more-potent antibiotics quinupristin-dalfopristin and linezolid on outcome measure of patients with vancomycin-resistant Enterococcus bacteremia. Clin Infect Dis 2008;46:30-6.

12. Clinical and Laboratory Standards Institute. Performance standards for antimicrobial susceptibility testing; Sixteenth Informational Supplement M100-S16. Wayne, PA; Clinical and Laboratory 
Standards Institute, 2006.

13. Koh EM, Lee SG, Kim CK, Kim M, Yong D, Lee K, et al. Microorganisms isolated from blood cultures and their antimicrobial susceptibility patterns at a university hospital during 1994-2003. Korean J Lab Med 2007;27:265-75.

14. Kang SH, Kim YR. Characteristics of microorganisms isolated from blood cultures at a university hospital located in an island region during 2003 2007. Korean J Clin Microbiol 2008;11:11-7.

15. Ahn GY, Jang SJ, Lee SH, Jeong OY, Chaulagain BP, Moon DS, et al. Trends of the species and antimicrobial susceptibility of microorganisms isolated from blood cultures of patients. Korean $\mathrm{J}$ Clin Microbiol 2006;9:42-50.

16. Karlowsky JA, Jones ME, Draghi DC, Thornsberry C, Sahm DF, Volturo GA. Prevalence and antimicrobial susceptibilities of bacteria isolated from blood cultures of hospitalized patients in the United States in 2002. Ann Clin Microbiol Antimicrob 2004;3:7.

17. Kang BK, Lee HJ, Suh JT. The trends of the species and antimicrobial susceptibility of bacteria and fungi isolated from blood cultures (1986-1996). Korean J Clin Pathol 1998;18:57-64.

18. Lee H, Kim CK, Lee J, Lee SH, Ahn JY, Hong SG, et al. Antimicrobial resistance of clinically important bacteria isolated from 12 hospitals in Korea in 2005 and 2006. Korean J Clin Microbiol 2007;10:59-69.

19. Lee K, Park KH, Jeong SH, Lim HS, Shin JH, Yong D, et al. Further increase of vancomycin-resistant Enterococcus faecium, amikacin- and fluoroquinolone-resistant Klebsiella pneumoniae, and imipenem-resistant Acinetobacter spp. in Korea: 2003 KONSAR surveillance. Yonsei Med J 2006;47:43-54.

20. Quale J, Landman D, Saurina G, Atwood E, DiTore V, Patel K. Manipulation of a hospital antimicrobial formulary to control an outbreak of vancomycin-resistant enterococci. Clin Infect Dis 1996;23:1020-5.

21. Aumeran C, Baud O, Lesens O, Delmas J, Souweine B, Traoré O. Successful control of a hospital-wide vancomycin-resistant
Enterococcus faecium outbreak in France. Eur J Clin Microbiol Infect Dis 2008;27:1061-4.

22. Bhavnani SM, Drake JA, Forrest A, Deinhart JA, Jones RN, Biedenbach DJ, et al. A nationwide, multicenter, case-control study comparing risk factors, treatment, and outcome for vancomycin-resistant and -susceptible enterococcal bacteremia. Diagn Microbiol Infect Dis 2000;36:145-58.

23. Olivier CN, Blake RK, Steed LL, Salgado CD. Risk of vancomycin-resistant Enterococcus (VRE) bloodstream infection among patients colonized with VRE. Infect Control Hosp Epidemiol 2008;29:404-9.

24. Fridkin SK, Edwards JR, Courval JM, Hill H, Tenover FC, Lawton $\mathrm{R}$, et al. The effect of vancomycin and third-generation cephalosporins on prevalence of vancomycin-resistant enterococci in 126 U.S. adult intensive care units. Ann Intern Med 2001; 135:175-83.

25. Peset V, Tallón P, Sola C, Sánchez E, Sarrión A, Pérez-Bellés C, et al. Epidemiological, microbiological, clinical, and prognostic factors of bacteremia caused by high-level vancomycin-resistant Enterococcus species. Eur J Clin Microbiol Infect Dis 2000;19: 742-9.

26. Edmond MB, Ober JF, Weinbaum DL, Pfaller MA, Hwang T, Sanford MD, et al. Vancomycin-resistant Enterococcus faecium bacteremia: risk factors for infection. Clin Infect Dis 1995;20: 1126-33.

27. Lee YJ, Lee JG, Hwang BY, Jeong HW, Jung SJ, Kee SY, et al. Clinical characteristics and risk factors of death among patients with vancomycin-resistant enterococci (VRE) during 8 years (1994-2001) in a university hospital. Infect Chemother 2003; $35: 249-55$.

28. Jun JB, Jeon MH, Kwon HH, Choi SH, Woo JH, Kim YS, et al. Vancomycin-resistant enterococcal bacteremia in a hematology unit: risk factors for mortality and impact of adequate antimicrobial therapy on mortality. Infect Chemother 2007;39:133-41. 
=국문초록=

\title{
2003 2007년 한 대학병원 혈액배양에서 분리된 장알균의 항균제 저항성 및 Vancomycin 내성 장알균 균혈증에 관여하는 위험인자 분석
}

\author{
경희대학교 의과대학 ${ }^{1}$ 경희의료원 진단검사의학과, ${ }^{2}$ 동서신의학병원 진단검사의학과
}

박경선 ${ }^{1}$, 김명희 ${ }^{2}$, 박태성 $^{1}$, 서진태 $^{1}$, 이희주 ${ }^{1}$

배경: Vancomycin 내성 장알균(vancomycin resistance enterococcus, VRE)은 1990년대 후반기부터 국내에서 꾸준히 증가하 여 중요한 병원 감염 관리 대상의 균주가 되었다. 따라서 저자들은 최근 5년간 한 대학병원의 혈액배양에서 분리된 장알 균의 항균제 내성 양상과 VRE 균혈증에 관련된 위험 인자를 분석해 보고자 하였다.

방법: 2003년 1월부터 2007년 12월까지 혈액에서 분리된 장알균의 항균제 내성 양상을 연도별로 분석하여 그 추이를 알아보았다 또한 VRE 균혈증의 위험인자를 분석하기 위해 다변량 로지스틱 회귀 분석을 이용하였다.

결과: 총 225균주의 장알균이 혈액에서 분리되었고 그 중에서 Enterococcus faecalis가 114균주(44.7\%), Enterococcus facium이 108균주(42.4\%), Enterococcus casseliflavus가 15균주(5.9\%), Enterococcus gallinarum이 12균주(4.7\%)였다. 또한 55균 주(21.6\%)가 vancomycin에 내성을 보였으며 연도별로 볼 때, 2004년과 2005년 vancomycin과 teicoplanin의 내성률은 각각 $33.3 \%$ 와 $27.3 \%, 34.4 \%$ 와 23.0\%로 높았고 2003년, 2006년 및 2007년에는 각각 $8.7 \%$ 와 $8.7 \%, 19.0 \%$ 와 $14.3 \%$ 및 $13.5 \%$ 와 $11.5 \%$ 로 상대적으로 낮았다. Vancomycin 감수성 장알균(vancomycin susceptible enterococcus, VSE) 균혈증이 있는 환자(55 명)를 대조군으로 하여 VRE 균혈증이 있는 환자(55명)를 다변량 분석의 방법으로 비교한 결과, E. faecium 균혈증이 있는 경우(OR 12.624, $P<0.001)$ 와 E. faecium과 E. faecalis를 제외한 다른 장알균 균혈증에 의한 경우(OR 21.473, $P=0.011)$ 가 $\mathrm{VRE}$ 균혈증에 통계적으로 유의한 위험인자로 분석되었다. 또한 연도별 장알균의 vancomycin에 대한 내성률의 차이를 분석하기 위해 병원 내 감염관리 정책 및 병원 환경의 변화를 고려해 보았다. 여러 요인 중에서 vancomycin과 quinupristin-dalfopristin의 항균제 사용을 제한하는 정책을 실시한 이후 vancomycin 내성률이 $27.78 \%$ 에서 $15.50 \%$ 로 통계적으로 유 의 $(P=0.0257)$ 하게 낮아진 것을 확인할 수 있었다.

결론: 저자들은 VRE 균혈증에 관여하는 위험인자에 대한 여러 연구들을 기반으로 감염관리 정책을 수립한다면 VRE 균혈증을 보다 효과적으로 통제할 수 있을 것이라 판단하였다. [대한임상미생물학회지 2010;13:59-67]

교신저자 : 이희주, 130-702, 서울시 동대문구 회기동 1

경희의료원 진단검사의학과

Tel: 02-958-8672, Fax: 02-958-8609

E-mail: leehejo@khmc.or.kr 